\title{
Article \\ Effects of Chromium Carbide Coatings on Microstructure and Thermal Conductivity of Mg/Diamond Composites Prepared by Squeeze Casting
}

\author{
Jianwei Li ${ }^{1}$, Ren Peng ${ }^{1}{ }^{\circledR}$, Jinming $\mathrm{Ru}^{2}$, Jianhua $\mathrm{Wu}^{3}{ }^{3}$, Kaixiang Zhou ${ }^{1}$, Yongxin Yan ${ }^{1}$, Xiaojing $\mathrm{Xu}^{1}$ \\ and Yuhua Zhou ${ }^{1, *}$ \\ 1 Institute of Advanced Manufacturing and Modern Equipment Technology, Jiangsu University, \\ Zhenjiang 212013, China; jwli4764@ujs.edu.cn (J.L.); 2221903048@stmail.ujs.edu.cn (R.P.); \\ 2221803079@stmail.ujs.edu.cn (K.Z.); 2222003135@stmail.ujs.edu.cn (Y.Y.); xjxu67@126.com (X.X.) \\ 2 Jones PLC Tech Yixing, Tengfei Road, Yixing 21420, China; hxsj116@163.com \\ 3 Advanced Materials Institute, Qilu University of Technology (Shandong Academy of Sciences), \\ Jinan 250014, China; jianhw@sdas.org \\ * Correspondence: zhouyuhua_ujs@126.com
}

Citation: Li, J.; Peng, R.; Ru, J.; Wu, J.; Zhou, K.; Yan, Y.; Xu, X.; Zhou, Y.

Effects of Chromium Carbide

Coatings on Microstructure and Thermal Conductivity of $\mathrm{Mg}$ /Diamond Composites Prepared by Squeeze Casting. Materials 2022, 15, 1284. https://doi.org/10.3390/ ma15041284

Academic Editors: Manoj Gupta, Tirumalai S. Srivatsan and Pradeep K. Rohatgi

Received: 6 January 2022

Accepted: 1 February 2022

Published: 9 February 2022

Publisher's Note: MDPI stays neutral with regard to jurisdictional claims in published maps and institutional affiliations.

Copyright: (C) 2022 by the authors. Licensee MDPI, Basel, Switzerland. This article is an open access article distributed under the terms and conditions of the Creative Commons Attribution (CC BY) license (https:// creativecommons.org/licenses/by/ $4.0 /)$.

\begin{abstract}
Magnesium matrix composites are considered a desired solution for lightweight applications. As an attractive thermal management material, diamond particle-reinforced $\mathrm{Mg}$ matrix ( $\mathrm{Mg} /$ diamond) composites generally exhibit thermal conductivities lower than expected. To exploit the potential of heat conduction, a combination of $\mathrm{Cr}$ coating on diamond particles and squeeze casting was used to prepare $\mathrm{Mg}$ /diamond $(\mathrm{Cr})$ composites. The thickness of the $\mathrm{Cr}$ coating under different coating processes $\left(950{ }^{\circ} \mathrm{C} / 30 \mathrm{~min}, 950{ }^{\circ} \mathrm{C} / 60 \mathrm{~min}, 950{ }^{\circ} \mathrm{C} / 90 \mathrm{~min}, 1000{ }^{\circ} \mathrm{C} / 30 \mathrm{~min}\right.$, and $1050{ }^{\circ} \mathrm{C} / 30 \mathrm{~min}$ ) was measured by FIB-SEM to be $1.09-2.95 \mu \mathrm{m}$. The thermal conductivity (TC) of the $\mathrm{Mg}$ /diamond composites firstly increased and then decreased, while the coefficient of thermal expansion (CTE) of $\mathrm{Mg}$ /diamond ( $\mathrm{Cr}$ ) composite firstly decreased and then increased with the increase in Cr coating thickness. The composite exhibited the maximum TC of $202.42 \mathrm{~W} /(\mathrm{m} \cdot \mathrm{K})$ with a $1.20 \mu \mathrm{m}$ Cr coating layer, while a minimum CTE of $5.82 \times 10^{-6} / \mathrm{K}$ was recorded with a coating thickness of $2.50 \mu \mathrm{m}$. The results clearly manifest the effect of $\mathrm{Cr}$ layer thickness on the TC and CTE of $\mathrm{Mg}$ /diamond composites.
\end{abstract}

Keywords: Mg/diamond composites; thermophysical properties; interface; squeeze casting

\section{Introduction}

The rapid development of the electronic field urgently requires the development of thermal management materials with high performance [1,2]. Carbon materials, including carbon fibers, graphite, diamond, carbon foams, carbon nanotubes, graphene, and reinforced metal matrix composites (MMCs) with high TC and low CTE, are the possible solution for electronic packaging applications [3,4]. Among them, diamond is an ideal reinforcement material due to its excellent intrinsic thermal conductivity $(1200-2000 \mathrm{~W} /(\mathrm{m} \cdot \mathrm{K}))$ and low thermal expansion coefficient $\left(2.3 \times 10^{-6} / \mathrm{K}\right)[5,6]$.

In the context of diamond-reinforced MMCs with high TC, magnesium and its alloys have long been neglected because of their intrinsic thermal conductivity being lower than that of $\mathrm{Al}$ and $\mathrm{Cu}$. Nevertheless, it still needs to be pointed out that the density of magnesium is much lower than that of aluminum and copper. Therefore, the development of diamond-reinforced magnesium matrix composites with high TC and low CTE can further broaden the applications of magnesium alloys [7,8].

Sound interfacial bonding is the basic prerequisite for achieving a metal/diamond composite with high TC. In order to improve the thermal conductivity, diamond surface coating [9-11] and metal matrix alloying [12-14] have been applied to enhance the interfacial bonding between the diamond and the metal matrix. The surface coating method 
excels in improving composite performance; Kumar et al. developed a series of zinc-based coatings such as $\mathrm{Zn}-\mathrm{WO}_{3}$ [15] and $\mathrm{Zn}-\mathrm{Ni}-\mathrm{WC}$ composite nanocoatings [16], which exhibit excellent corrosion resistance and high hardness, greatly expanding the application of steel in boat structures, manufacturing, nuclear power plants, etc. Studies have shown that the addition of alloying elements can drastically reduce the TC of the magnesium matrix [17]. However, it is a feasible method to coat $\mathrm{Ti}, \mathrm{Mo}, \mathrm{W}, \mathrm{Zr}, \mathrm{Al}, \mathrm{Cr}$, and other carbide-forming elements onto the diamond surface to improve the wettability between the $\mathrm{Mg}$ matrix and the diamond [18]. Moreover, it has been reported that $\mathrm{Cr}$ coatings have good mechanical stability [19] and thermal conductivity [20].

To the best of our knowledge, there are few reports on the TC of $\mathrm{Mg} /$ diamond composites. Stevenson [21] prepared a $\mathrm{Mg}-5.5 \mathrm{Zn}-0.5 \mathrm{Zr} /$ diamond composite and found that the TC of the composite was not improved by the addition of alloying elements in the matrix. Pickard [22] claimed in his patent that, when the diamond volume fraction is $54 \%$, the TC of the composite can be increased from $120-250 \mathrm{~W} /(\mathrm{m} \cdot \mathrm{K})$ to $520-550 \mathrm{~W} /(\mathrm{m} \cdot \mathrm{K})$ by coating SiC on the diamond surface. Molina et al. [7] coated Ti on the diamond surface and prepared $\mathrm{Mg}$ /diamond composites by gas pressure infiltration, thereby greatly improving the thermal conductivity of the composite. Zhu et al. [11] used a molten salt method to successfully prepare surface-gradient-modified diamond particles. The value of the thermal conductivity of the surface-modified $\mathrm{Mg}$ /diamond composites with a diamond volume percentage of $35 \%$ reached $286 \mathrm{~W} /(\mathrm{m} \cdot \mathrm{K})$. Ma et al. [23] studied the thermal conductivity and mechanical properties of ND-reinforced ZK60 matrix composites; the thermal conductivity of the composite material exceeded $129 \mathrm{~W} /(\mathrm{m} \cdot \mathrm{K})$ with an ND content of $0.05 \%$. In these cases, the TC values of the $\mathrm{Mg}$ /diamond composites were lower than the predicted values. It is, hence, necessary to understand the influence of interfacial carbide evolution on the thermal conductivity.

Numerous efforts have been devoted to improving the thermal conductivity of metal matrix composites; however, there is a paucity of research literature on magnesium-based composites. The commonly used coating methods for diamond surfaces include the molten salt method, vacuum micro-evaporation, chemical vapor deposition, magnetron sputtering, and sol-gel [24,25]. The molten salt method is one of the most commonly used coating methods due to its low cost. However, the effect of the molten salt method on the structure of chromium coating and the $\mathrm{TC}$ of $\mathrm{Mg}$ /diamond composites has not been studied yet. Therefore, solving this problem will accelerate the application of high-TC electronic packaging materials in the semiconductor, integrated circuit, and aerospace industries.

In the present work, we coated $\mathrm{Cr}$ on diamond particles to improve the interface bonding and prepared the composites using the squeeze casting infiltration process. The thickness of the coating in the range 1.09-2.95 $\mu \mathrm{m}$ was measured by FIB-SEM to explore the effect of coatings with different thicknesses on the thermal properties of the $\mathrm{Mg} /$ diamond composites.

\section{Materials and Methods}

Commercially available bulk Mg (purity: 99.95 wt.\%, Shanxi Yinguang Huasheng Magnesium Co., Yuncheng, China) was used as a metal matrix, and HHD90-type synthetic single-crystalline diamond powders (particle size: 212-250 $\mu \mathrm{m}$, Henan Huanghe Whirlwind Co., Changge, China) were used to reinforce the composite. $\mathrm{NaCl}$ and $\mathrm{KCl}$ were used as analyitical reagents (Sinopharm Chemical Reagent Co., Ltd., Zhenjiang, China). NaCl and $\mathrm{KCl}$ with a molar ratio of 1:1 were mixed and used to cover the diamond particles for the salt bath. Two different sizes of alumina crucibles were nested and used, and the gap was filled with mixed salt.

\subsection{Preparation of $\mathrm{Cr}$ Coating on Diamond Powder}

The $\mathrm{Cr}$ coating was deposited onto the diamond particles using the molten salt method. When the temperature is higher than $850{ }^{\circ} \mathrm{C}$, the diamond particles react with $\mathrm{Cr}$ powder to form carbides [26]. Thus, the coating temperature and coating time were $950-1050{ }^{\circ} \mathrm{C}$ 
and 30-90 min. The coating process can be described by the following steps: (i) the diamond particles were washed with a diluted acid to remove impurities; (ii) the salt and diamond/Cr powder mixture was placed in an alumina crucible, heating to different temperatures $\left(950^{\circ} \mathrm{C}, 1000^{\circ} \mathrm{C}\right.$, and $1050^{\circ} \mathrm{C}$ ) for 30-90 $\mathrm{min}$ in a tube furnace, before furnacecooling to room temperature; (iii) after cooling, the mixture was separated by an ultrasonic wave with boiling distilled water and alcohol, and then the coated diamond particles were dried under vacuum at $100{ }^{\circ} \mathrm{C}$ for $30 \mathrm{~min}$.

\subsection{Preparation of $\mathrm{Mg} /$ Diamond ( $\mathrm{Cr}$ ) Composites}

The $\mathrm{Mg}$ /diamond composites were prepared using the squeeze casting infiltration process. The main process included two steps. Firstly, the $\mathrm{Cr}$-coated diamond particles were densely packed in a graphite mold, and the pure $\mathrm{Mg}$ bulks were placed on top of the diamond preform in a quartz crucible. Secondly, considering that pure magnesium is easily oxidized and magnesium liquid can splash easily, the crucible was placed in a resistance furnace, heated to $800{ }^{\circ} \mathrm{C}$, and kept for 10 min under a $\mathrm{SF}_{6}+\mathrm{CO}_{2}$ protective gas mixture (volume ratio of $\left.\mathrm{SF}_{6} / \mathrm{CO}_{2}=1: 99\right)$. Then, a uniaxial pressure $(10 \mathrm{MPa}$ ) was held for $60 \mathrm{~s}$ at $800{ }^{\circ} \mathrm{C}$ until the infiltration process was accomplished. Finally, the sample was obtained after the graphite mold was cooled to room temperature. The specific raw materials and experimental parameters are shown in Table 1.

Table 1. Raw materials and experimental parameters.

\begin{tabular}{|c|c|c|c|c|}
\hline \multicolumn{4}{|c|}{ Raw Materials } & \multirow{2}{*}{$\begin{array}{l}\text { Experimental Parameters } \\
\text { Coating time-30-90 min } \\
\text { ating temperature-950-1050 }{ }^{\circ} \mathrm{C}\end{array}$} \\
\hline & purity & Size $(\mu \mathrm{m})$ & TC value $(\mathrm{W} /(\mathrm{m} \cdot \mathrm{K}))$ & \\
\hline Diamond & - & 230 & 1800 & Preparation temperature $-800^{\circ} \mathrm{C}$ \\
\hline $\mathrm{Mg}$ & $>99.95 \%$ & - & 156 & holding time $-10 \mathrm{~min}$ \\
\hline $\mathrm{Cr}$ & $>99.99 \%$ & 70 & - & infiltration pressure- $10 \mathrm{MPa}$ \\
\hline $\mathrm{NaCl}$ & $>99.99 \%$ & - & - & infiltration time $-60 \mathrm{~s}$ \\
\hline $\mathrm{KCl}$ & $>99.99 \%$ & - & - & graphite mold $-\varphi 20 \mathrm{~mm} \times 4 \mathrm{~mm}$ \\
\hline
\end{tabular}

\subsection{Characterization}

The microstructures of the uncoated diamond particles, the coated diamond particles, and the diamond extracted from the composite material were observed with a field-emission scanning electron microscope (FE-SEM, JSM-7001F, JEOL Ltd., Tokyo, Japan). The phase compositions of the diamond $(\mathrm{Cr})$ particles and the $\mathrm{Mg}$ /diamond $(\mathrm{Cr})$ composites were characterized by $\mathrm{X}$-ray diffraction with $\mathrm{Cu}-\mathrm{K} \alpha$ radiation (XRD, D8-ADVANCE, Burker Co., Karlsruhe, Germany). The cross-section of a layer was prepared using a focused ion beam system (FIB-SEM, ZEISS Crossbeam 350, Zeiss Co., Oberkochen, Germany), and the coating thickness was also obtained.

The thermal conductivity of the composites was calculated using the equation $K_{c}=\alpha \cdot \rho_{c} \cdot c$, where $K_{c}, \alpha, \rho_{c}$, and $c$ represent thermal conductivity, thermal diffusivity, sample density, and heat capacity, respectively. The thermal diffusivity was measured using a laser flash apparatus (LFA 457, NETZSCH Group, Selb, Germany) at room temperature with disc-shaped samples of $\Phi 12.7 \mathrm{~mm} \times 2.5 \mathrm{~mm}$. The density of the composite material was measured using the Archimedes drainage method, with absolute ethanol as the liquid medium, an analytical balance with an accuracy of $0.1 \mathrm{mg}$, and the attached density measuring component. The specific heat capacity of the composite material can be calculated theoretically from the mass fraction of each component using the equation $C=C_{\text {diamond }} \cdot W_{\text {diamond }}+C_{M g} \cdot W_{M g}$, where $C_{\text {diamond }}$ and $C_{M g}$ represent the specific heat capacity of diamond and $\mathrm{Mg}$, and $W_{\text {diamond }}$ and $W_{M g}$ represent the mass fraction of diamond and $\mathrm{Mg}$, respectively. The above variables were averaged from three measurements to calculate the thermal conductivity of the $\mathrm{Mg}$ /diamond composites. The thermal expansion coefficient of the composite mate- 
rial was measured in the range $300-573 \mathrm{~K}$ with a heating rate of $10 \mathrm{~K} \cdot \mathrm{min}^{-1}$ in an argon atmosphere using a cuboid sample of $15 \mathrm{~mm} \times 3 \mathrm{~mm} \times 3 \mathrm{~mm}$ machined by laser cutting.

\section{Results}

Figure 1 shows SEM images of the Cr-coated diamond particles. When the coating temperature reached $950{ }^{\circ} \mathrm{C}$, the $\mathrm{Cr}$ coating successfully adhered to the diamond surface, and the thickness increased with holding time. However, most of the diamond surface coating structure was incomplete at $950{ }^{\circ} \mathrm{C}$, and almost all coatings were cracked, as shown in Figure 1a. With an increase in the holding time $(90 \mathrm{~min})$, the irregular island-like structure of the diamond (100) crystal plane became smoother and denser, and the number of cracks on the diamond surface decreased significantly, as shown in Figure 1e. This shows that, under these process conditions, an appropriate increase in holding time increases the thickness of the coating and optimizes the bond strength between the coating and the diamond surface, thus making the coating more complete.

We also investigated the effect of temperature on the formation of the coating. As the coating temperature was increased, the diamond surface gradually formed a complete coating. At $950{ }^{\circ} \mathrm{C}$, the diamond (111) surface was rough but complete, while the (100) surface had unnucleated pits, and the coating was broken. Moreover, the reaction between diamond and $\mathrm{Cr}$ was anisotropic. The (100) crystal plane of diamond had higher activity and reacted more easily with metallic $\mathrm{Cr}$ than the (111) face. Above $1000{ }^{\circ} \mathrm{C}$, the edges and corners between the diamond crystal planes become rounded, and the surface roughness decreased; in particular, the coating on the (100) crystal plane became complete. This shows that the increase in temperature sped up the diffusion and deposition of $\mathrm{Cr}$ to the diamond surface in the molten salt, such that the thickness of the coating was increased continuously. As the coating temperature further increased to $1050^{\circ} \mathrm{C}$, the originally uniform and dense coating thickened while cracks also developed, and some powder-like substance appeared on the (100) crystal plane, as shown in Figure 1i. It can be seen that diamond particles prepared at too high a salt bath temperature caused coating cracking due to the excessive temperature difference in the subsequent extraction process. At the same time, when the thickness of the coating was increased to a certain extent, it hindered the continuous reaction of $\mathrm{Cr}$ and diamond. A certain amount of $\mathrm{Cr}$ powder remained on the surface of the coating. From the above analysis, it can be found that the formation of the diamond surface coating is controlled by the diffusion mechanism, and the temperature has an important influence on the microscopic morphology of the coating.

This shows that an excessive temperature and hold time would lead to cracks in the coating in the subsequent extraction process. When the thickness of the coating reaches a certain level, it hinders further reaction between the chromium and the diamond. It can be concluded that temperature and hold time have an important influence on the formation and microscopic morphology of the coatings.

In the coating process, the diamond powder and $\mathrm{Cr}$ come into contact and react. In the temperature range 298-1800 K, the Gibbs energies of the reaction between diamond and $\mathrm{Cr}$ powder were as shown in Table 2 . When the coating temperature was $950{ }^{\circ} \mathrm{C}, 1000{ }^{\circ} \mathrm{C}$, and $1050^{\circ} \mathrm{C}$, the Gibbs free energy of all reactions was negative, indicating that the three carbides of $\mathrm{Cr}_{3} \mathrm{C}_{2}, \mathrm{Cr}_{7} \mathrm{C}_{3}$, and $\mathrm{Cr}_{23} \mathrm{C}_{6}$ could form spontaneously.

Table 2. Gibbs energies of formation of chromium carbides.

\begin{tabular}{cc}
\hline Chemical Equations & Gibbs Functions \\
\hline $3 C r_{(s)}+2 C_{(s)}=C r_{3} C_{2(s)}$ & $\Delta G_{T}^{0}=-95.95-0.0198 T(\mathrm{KJ} / \mathrm{mol})$ \\
$7 C r_{(s)}+3 C_{(s)}=C r_{7} C_{3(s)}$ & $\Delta G_{T}^{0}=-182.5-0.0429 T(\mathrm{KJ} / \mathrm{mol})$ \\
$23 C r_{(s)}+6 C_{(s)}=C r_{23} C_{6(s)}$ & $\Delta G_{T}^{0}=-398.43-0.0827 T(\mathrm{KJ} / \mathrm{mol})$ \\
\hline
\end{tabular}



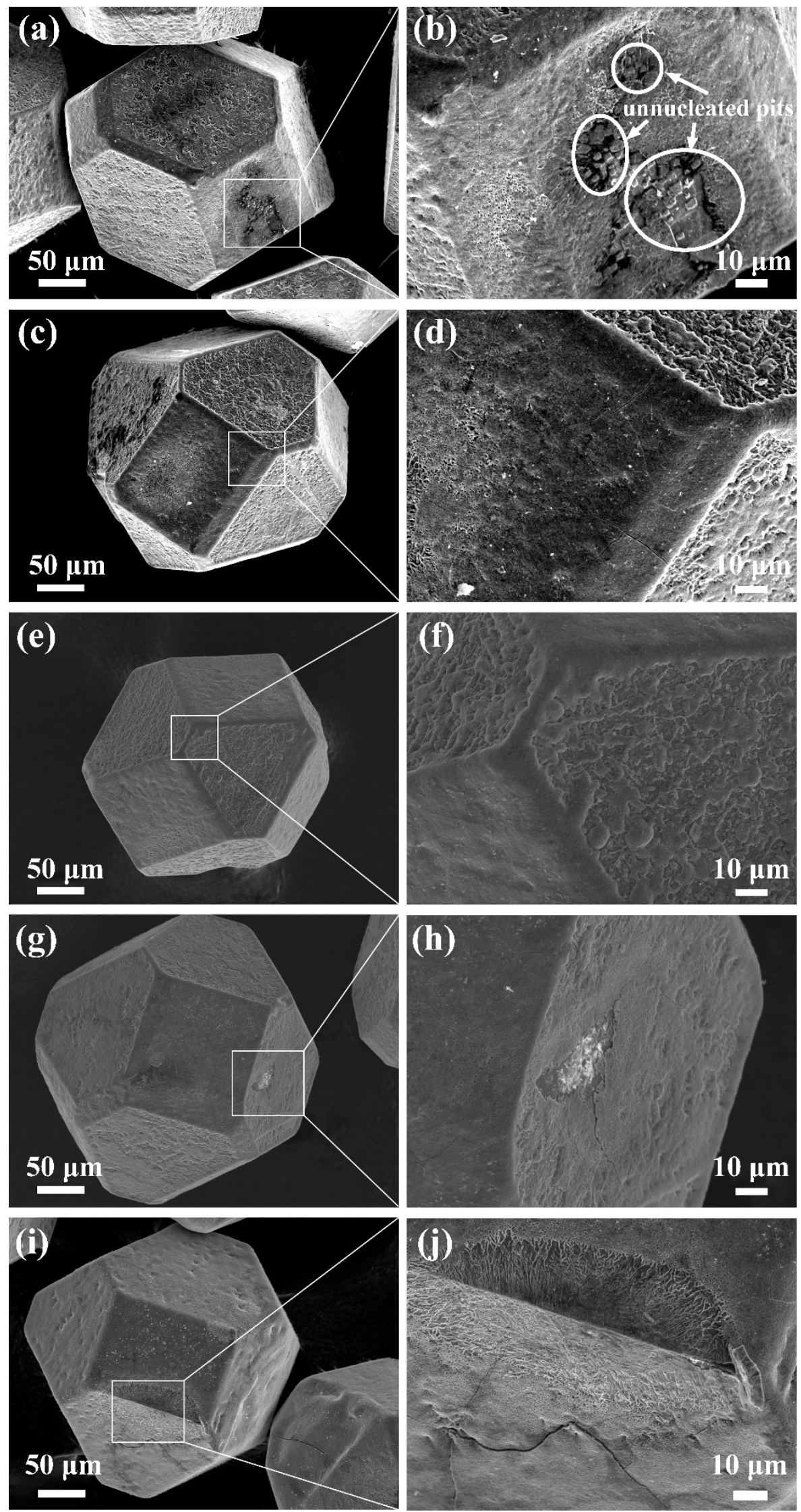

Figure 1. Cr coating diamond surface morphology under salt bath process with different parameters: (a,b) $950{ }^{\circ} \mathrm{C} / 30 \mathrm{~min},(\mathbf{c}, \mathbf{d}) 950{ }^{\circ} \mathrm{C} / 60 \mathrm{~min},(\mathbf{e}, \mathbf{f}) 950{ }^{\circ} \mathrm{C} / 90 \mathrm{~min},(\mathbf{g}, \mathbf{h}) 1000{ }^{\circ} \mathrm{C} / 30 \mathrm{~min}$, and (i,j) $1050{ }^{\circ} \mathrm{C} / 30 \mathrm{~min}$. 
In order to determine the phase composition of the diamond, we conducted XRD analysis as shown in Figure 2. The diffraction peaks of $\mathrm{Cr}_{3} \mathrm{C}_{2}$ and $\mathrm{Cr}_{7} \mathrm{C}_{3}$ appeared at the coating temperature of $950{ }^{\circ} \mathrm{C}$. However, that of $\mathrm{Cr}_{23} \mathrm{C}_{6}$ was not found, and it can be seen that the change in holding time only changed the intensity of each diffraction peak. With increasing coating temperature, $\mathrm{C}$ atoms detached from the coating and participated in the reaction with $\mathrm{Cr}$ atoms to form carbides with higher $\mathrm{C}$ content. The intensity of the two diffraction peaks did not change much at $100{ }^{\circ} \mathrm{C}$ and $1050{ }^{\circ} \mathrm{C}$, but the amount of $\mathrm{Cr}_{7} \mathrm{C}_{3}$ was significantly greater than that of $\mathrm{Cr}_{3} \mathrm{C}_{2}$. Combined with the Gibbs free energy analysis, the results show that $\mathrm{Cr}_{7} \mathrm{C}_{3}$ was easier to generate than $\mathrm{Cr}_{3} \mathrm{C}_{2}$ at the same temperature. This is also consistent with the results of thermodynamic analysis. During the reaction of diamond and $\mathrm{Cr}, \mathrm{Cr}_{23} \mathrm{C}_{6}$ was the first product formed, which was then gradually transformed into $\mathrm{Cr}_{7} \mathrm{C}_{3}$ and $\mathrm{Cr}_{3} \mathrm{C}_{2}$ with the increase in temperature, but the content of $\mathrm{Cr}_{7} \mathrm{C}_{3}$ was significantly higher than that of $\mathrm{Cr}_{3} \mathrm{C}_{2}$.

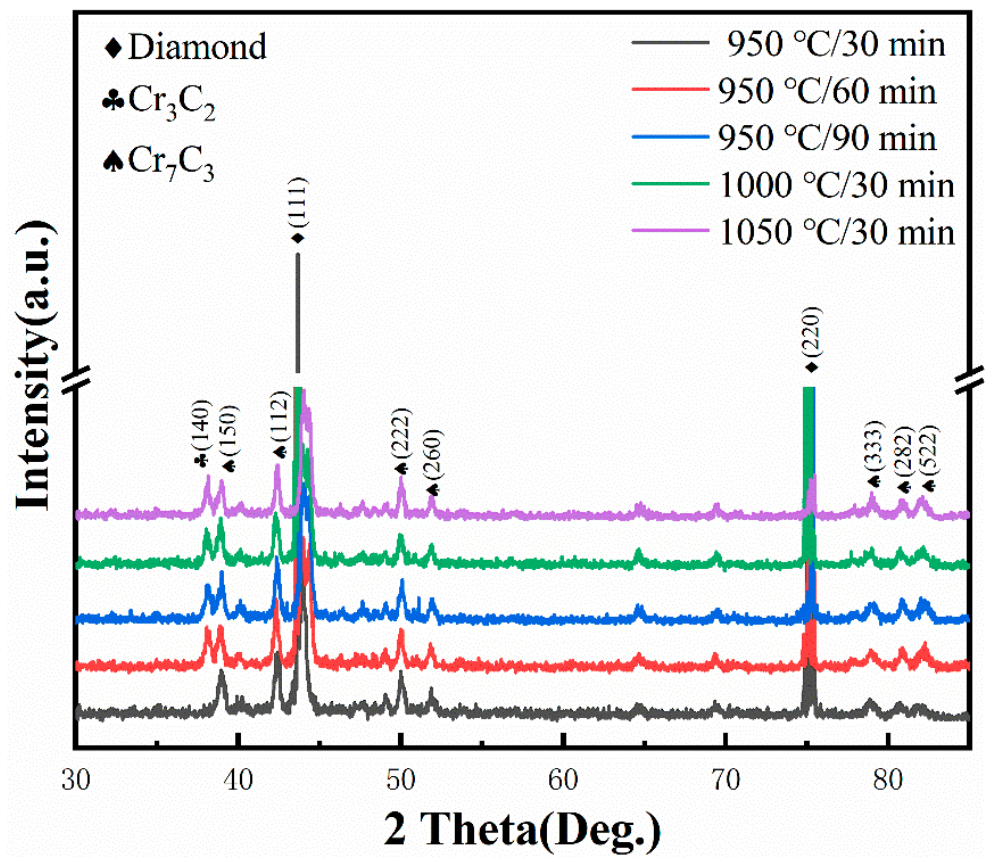

Figure 2. XRD patterns of diamond particles coated at $950-1050{ }^{\circ} \mathrm{C}$.

The film thickness of the Cr-coated diamond particles prepared under different processes was characterized and measured to more accurately quantify the influence of the coating process on the thickness of the coating. In previous studies, researchers mainly used SEM observation and the spherical weight gain method to estimate the thickness of the film $[7,27]$. However, it is difficult to directly observe the thickness of the film under a scanning electron microscope due to the typical hexahedral-octahedral structure of diamond, leading to the theoretical calculation method having an error. Therefore, in this paper, a focused ion beam (FIB) and scanning electron microscope (SEM) were coupled into an FIB-SEM dual-beam system. The high-current ion beam was used to strip the atoms on the diamond surface to achieve the interception of the microscopic cross-section of the coating structure, and then the cross-sectional layer shape was observed by scanning electron microscope, while the cross-sectional layer was analyzed by EDS line scanning. According to the change in element content, the thickness of the coating was accurately determined.

The SEM image and EDS line scan analysis results of the coating are shown in Figure 3, revealing that the thickness of the coating increased significantly with the increase in temperature but did not change significantly with the holding time. The EDS line scan was performed from the inside to the outside, suggesting that the $C$ content gradually decreased while the $\mathrm{Cr}$ content gradually increased. It can be observed that the $\mathrm{C}$ content tended to increase slightly after the decrease, which is because some of the $\mathrm{C}$ atoms in 
the diamond and some of the $\mathrm{Cr}$ atoms in the coating diffused into each other at the interface, thus reasonably forming carbides on both sides of the interface. The $\mathrm{Cr}$ element was observed at $1.09 \mu \mathrm{m}, 1.20 \mu \mathrm{m}, 1.85 \mu \mathrm{m}, 2.50 \mu \mathrm{m}$, and $2.95 \mu \mathrm{m}$ in the coatings at the three temperatures; accordingly, when the coating temperature was $950{ }^{\circ} \mathrm{C} / 30 \mathrm{~min}$, $950{ }^{\circ} \mathrm{C} / 60 \mathrm{~min}, 950^{\circ} \mathrm{C} / 90 \mathrm{~min}, 1000^{\circ} \mathrm{C} / 30 \mathrm{~min}$, and $1050^{\circ} \mathrm{C} / 30 \mathrm{~min}$, the coating thickness was $1.09 \mu \mathrm{m}, 1.20 \mu \mathrm{m}, 1.85 \mu \mathrm{m}, 2.50 \mu \mathrm{m}$, and $2.95 \mu \mathrm{m}$, respectively.
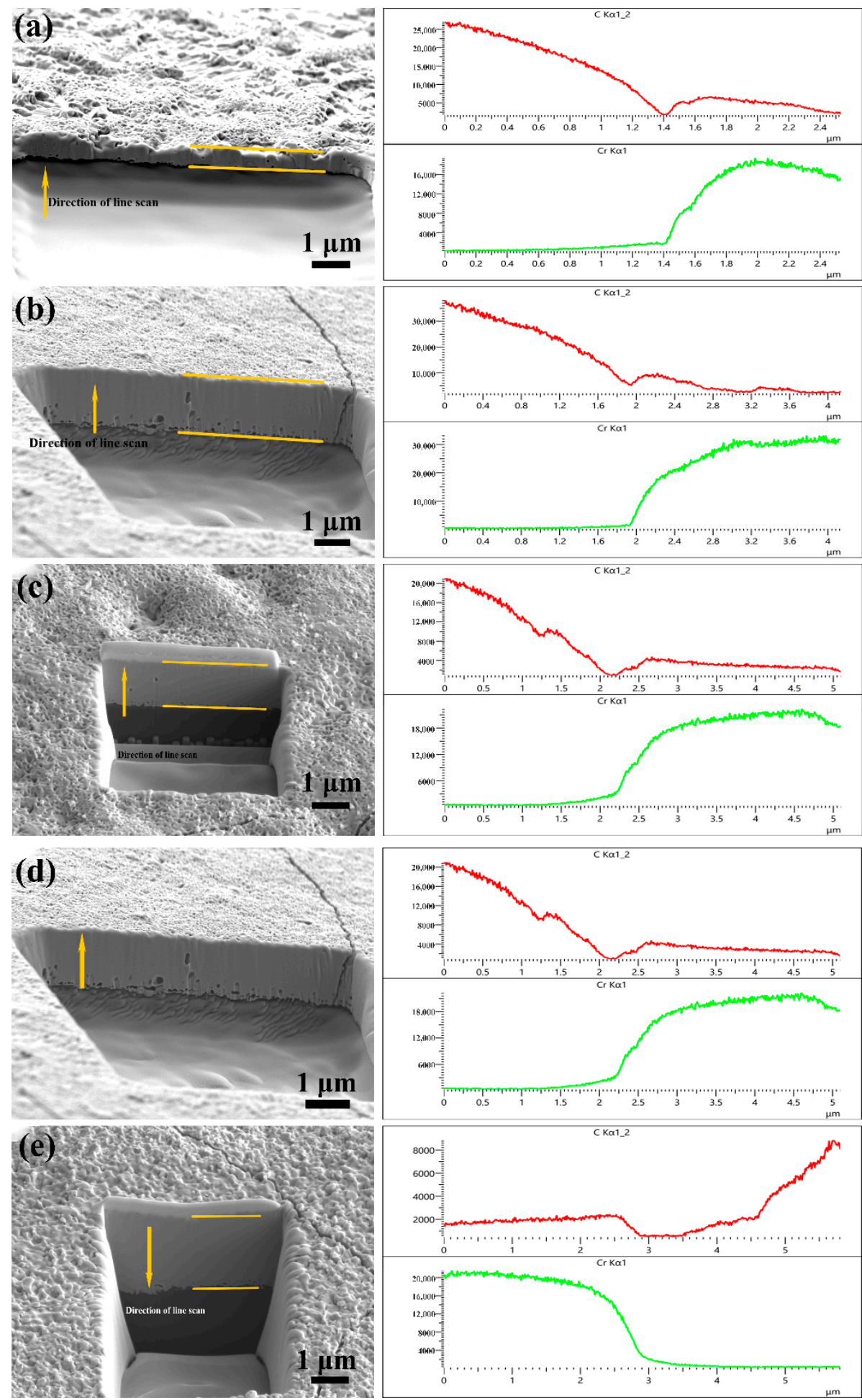

Figure 3. Micromorphology and EDS linear analysis of the coating with various coating parameters: (a) $950{ }^{\circ} \mathrm{C} / 30 \mathrm{~min}$, (b) $950{ }^{\circ} \mathrm{C} / 60 \mathrm{~min}$, (c) $950{ }^{\circ} \mathrm{C} / 90 \mathrm{~min}$, (d) $1000^{\circ} \mathrm{C} / 30 \mathrm{~min}$, and (e) $1050{ }^{\circ} \mathrm{C} / 30 \mathrm{~min}$. 
The microstructure of the composite material was characterized by SEM. As shown in Figure 4 , in the uncoated $\mathrm{Mg}$ /diamond composite, the distribution of diamond particles in the matrix was uneven, and there were many pits on the surface. Moreover, the fracture surface shows that there were several holes and voids, and diamond particle shedding resulted in dimples. However, diamond particles were homogeneously distributed and tightly bound in the composites after $\mathrm{Cr}$ coating. The introduction of the carbide layer improved the interface bonding, but the mismatch in thermal expansion coefficient between the thick coating and diamond resulted in poor bonding, which indirectly affected the interface bonding strength of the composite and even led to severe interface separation. On the basis of the investigation of the fracture surfaces of composites, it can be speculated that the effect of holding time on the interfacial bond strength of the composites was less significant compared to the influence of coating temperature.
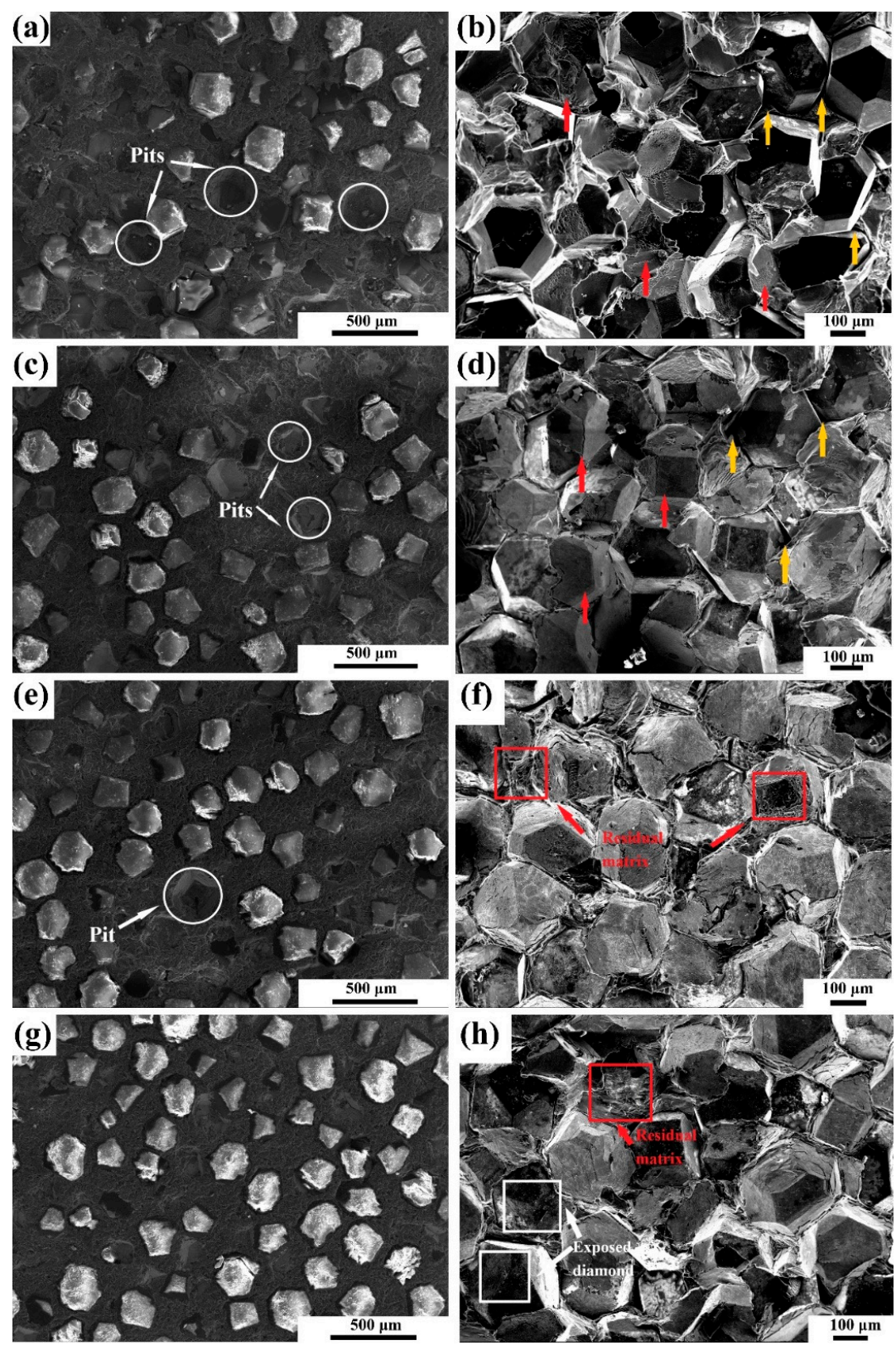

Figure 4. Cont. 

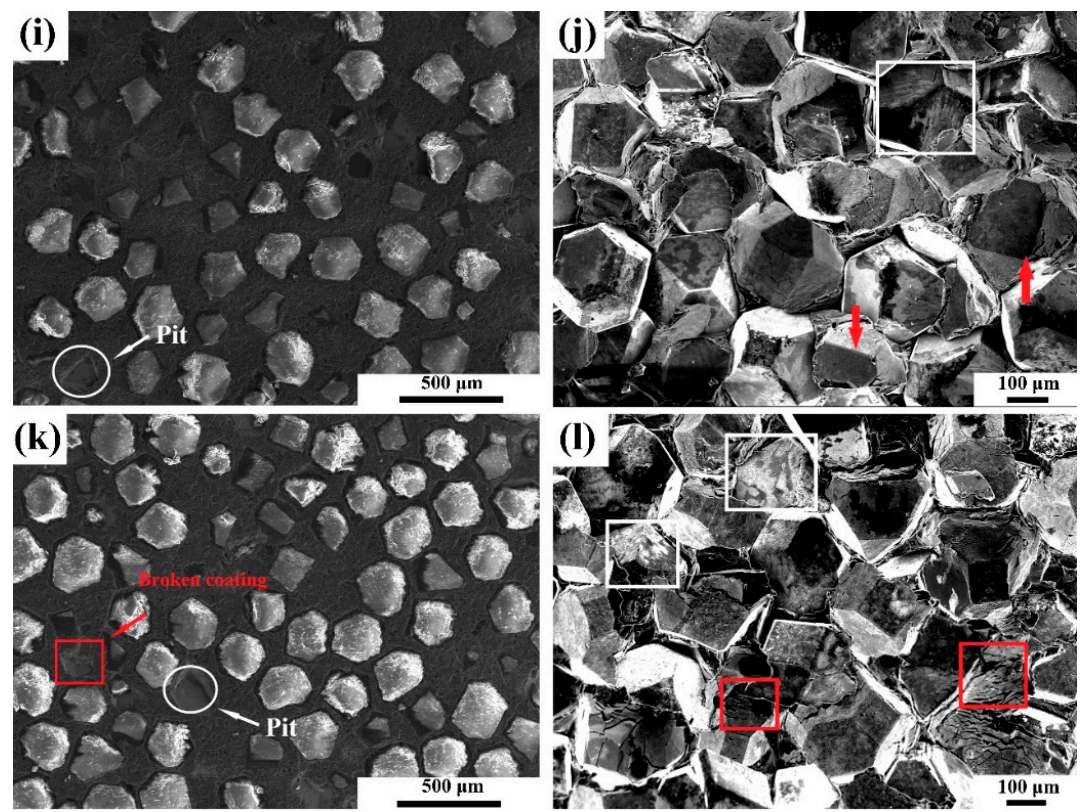

Figure 4. Microstructure and fracture surface of $\mathrm{Mg}$ /diamond composite with different coating temperatures: (a,b) uncoated, (c,d) $950{ }^{\circ} \mathrm{C} / 30 \mathrm{~min},(\mathbf{e}, \mathbf{f}) 950{ }^{\circ} \mathrm{C} / 60 \mathrm{~min},(\mathbf{g}, \mathbf{h}) 950{ }^{\circ} \mathrm{C} / 90 \mathrm{~min}$, (i,j) $1000{ }^{\circ} \mathrm{C} / 30 \mathrm{~min}$, and $(\mathbf{k}, \mathbf{l}) 1050{ }^{\circ} \mathrm{C} / 30 \mathrm{~min}$.

To study the phase composition of $\mathrm{Mg} /$ diamond $(\mathrm{Cr})$ composites at different coating temperatures, phase analysis was carried out by $X R D$, as shown in Figure $5 . \mathrm{Cr}_{3} \mathrm{C}_{2}, \mathrm{Cr}_{7} \mathrm{C}_{3}$, diamond, and $\mathrm{Mg}$ were identified in all composite samples. Surprisingly, the intensity of $\mathrm{Cr}_{7} \mathrm{C}_{3}$ was significantly lower than that of $\mathrm{Cr}_{3} \mathrm{C}_{2}$, which may be because the residual $\mathrm{Cr}$ atoms continued to undergo carbide transformation during the insulation stage of the $\mathrm{Mg}$ /diamond composite, thus generating a portion of $\mathrm{Cr}_{3} \mathrm{C}_{2}$. In particular, the $\mathrm{Cr}_{3} \mathrm{C}_{2}$ phase was observed with an intense peak at $82.2^{\circ}$ in the XRD pattern when the temperature was kept at $950{ }^{\circ} \mathrm{C}$ for $90 \mathrm{~min}$, indicating that, as the holding time increased, the interface layer continued to transform to carbides with high $\mathrm{C}$ content.

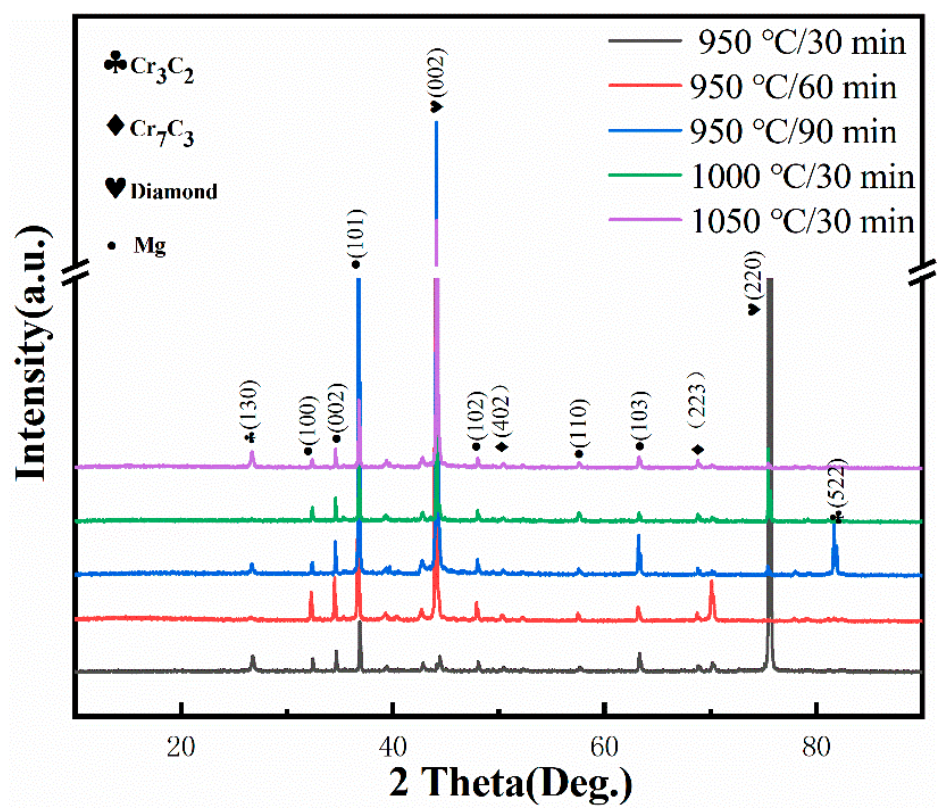

Figure 5. XRD patterns of $\mathrm{Mg}$ /diamond $(\mathrm{Cr})$ composites with various coating parameters.

The TC of the $\mathrm{Mg} /$ diamond $(\mathrm{Cr})$ composite increased first and then decreased as the thickness of the coating increased, as shown in Figure 6, attaining a maximum TC of 
202.42 W/(m·K) at $1.20 \mu \mathrm{m}$ coating thickness when $950{ }^{\circ} \mathrm{C} / 60 \mathrm{~min}$. The TC of the uncoated $\mathrm{Mg} /$ diamond composite was only $111.77 \mathrm{~W} /(\mathrm{m} \cdot \mathrm{K})$, owing to the poor wettability between the $\mathrm{Mg}$ matrix and the diamond. The coating thickness affects the thermal conductivity $\mathrm{Mg}$ /diamond $(\mathrm{Cr})$ composite to a certain extent, whereby a suitable coating thickness can improve the interface bonding, but an excessively thick coating can bring about a larger interface thermal resistance. In other words, the negative effect of the interface thermal resistance is stronger than the positive effect of the carbide layer, resulting in a decrease in thermal conductivity. In addition, according to the results of the interface analysis of the $\mathrm{Mg}$ /diamond $(\mathrm{Cr})$ composite, the coating obtained at high temperature already had defects such as cracking and peeling, which would form pores at the $\mathrm{Mg} / \mathrm{diamond}$ $(\mathrm{Cr})$ composite interface or even result in a discontinuous interface. In the heat transfer process, the interface defects can cause serious scattering effects on the coupling of electrons and phonons, as well as weaken the thermal conductivity of the composite. The thermal conductivity of the $\mathrm{Mg}$ /diamond composite with a coating thickness of $2.95 \mu \mathrm{m}$ was only $120.6 \mathrm{~W} /(\mathrm{m} \cdot \mathrm{K})$, which is consistent with the differential effective medium (DEM) model analysis [28].

$$
1-V_{p}\left(\frac{K_{c}}{K_{m}}\right)^{\frac{1}{3}}=\frac{K_{p}^{e f f}-K_{c}}{K_{p}^{e f f}-K_{m}} \text { with } K_{p}^{e f f}=\frac{K_{p}}{1+2 \frac{K_{p}}{h d}},
$$

where $K_{c}, K_{m}$, and $K_{p}$ are the thermal conductivities of the composite, matrix, and reinforcement, respectively. $V_{p}$ and $K_{p}^{e f f}$ are the volume fraction of the reinforcement and actual thermal conductivity of the reinforcement, respectively. As calculated using the differential effective medium (DEM) model, the interface thermal resistance of the $\mathrm{Mg} /$ diamond $(\mathrm{Cr})$ composite increased as the thickness of the coating increased, and the theoretical thermal conductivity of the $\mathrm{Mg}$ /diamond ( $\mathrm{Cr}$ ) composite gradually decreased. Theoretical calculations of the thermal conductivity were much higher than the experimental values, with even the TC of the unmodified $\mathrm{Mg} /$ diamond composite reaching $878 \mathrm{~W} /(\mathrm{m} \cdot \mathrm{K})$. This may be because of $\mathrm{Cr}_{3} \mathrm{C}_{2}$ and $\mathrm{Cr}_{7} \mathrm{C}_{3}$ coexisting in the coating, whereas the DEM model did not take into account the interface defects.

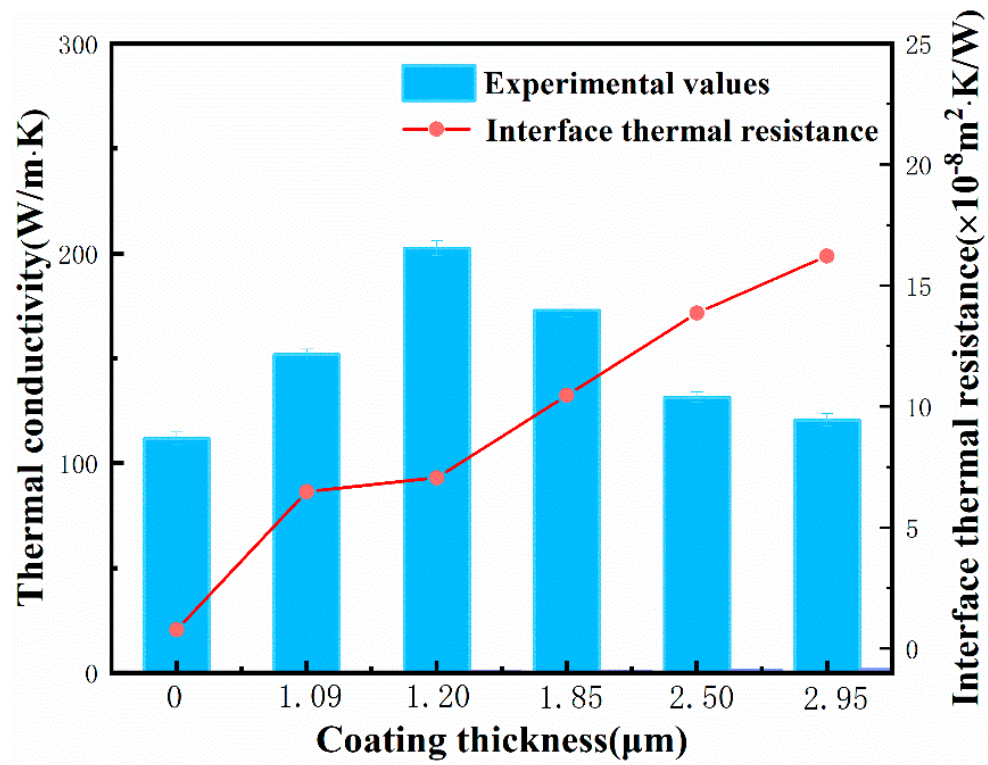

Figure 6. Thermal conductivity and interface thermal resistance of $\mathrm{Mg}$ /diamond ( $\mathrm{Cr}$ ) composites with different thicknesses of carbides.

The CTE of the $\mathrm{Mg}$ /diamond(Cr) and the unmodified $\mathrm{Mg}$ /diamond composites was measured, as shown in Figure 7a. The CTE of the uncoated Mg/diamond composite was as high as $24.95 \times 10^{-6} / \mathrm{K}$ at $573 \mathrm{~K}$. This was attributed to the extreme disparity in the CTE values of diamond $\left(1.3 \times 10^{-6} / \mathrm{K}\right)[6]$ and $\mathrm{Mg}\left(27.3 \times 10^{-6} / \mathrm{K}\right)$ [29], which could easily lead 
to rapid expansion of the matrix under the condition of poor interface bonding. The CTE of the $\mathrm{Mg}$ /diamond $(\mathrm{Cr})$ composite was only $5.82 \times 10^{-6} / \mathrm{K}$ at $2.50 \mu \mathrm{m}$ coating thickness, and, with the increase in temperature, the rate of increase in CTE was significantly slower, suggesting that a strong interface bond was formed between the interfaces of the composite at $1000{ }^{\circ} \mathrm{C} / 30 \mathrm{~min}$. The CTE value of the composite material was higher at $2.95 \mu \mathrm{m}$ coating thickness. This was due to the interface layer carbide itself having brittleness. The excessively thick coating structure caused the interface layer to crack, resulting in a separation of the interface between the matrix and the reinforcement.

(a)

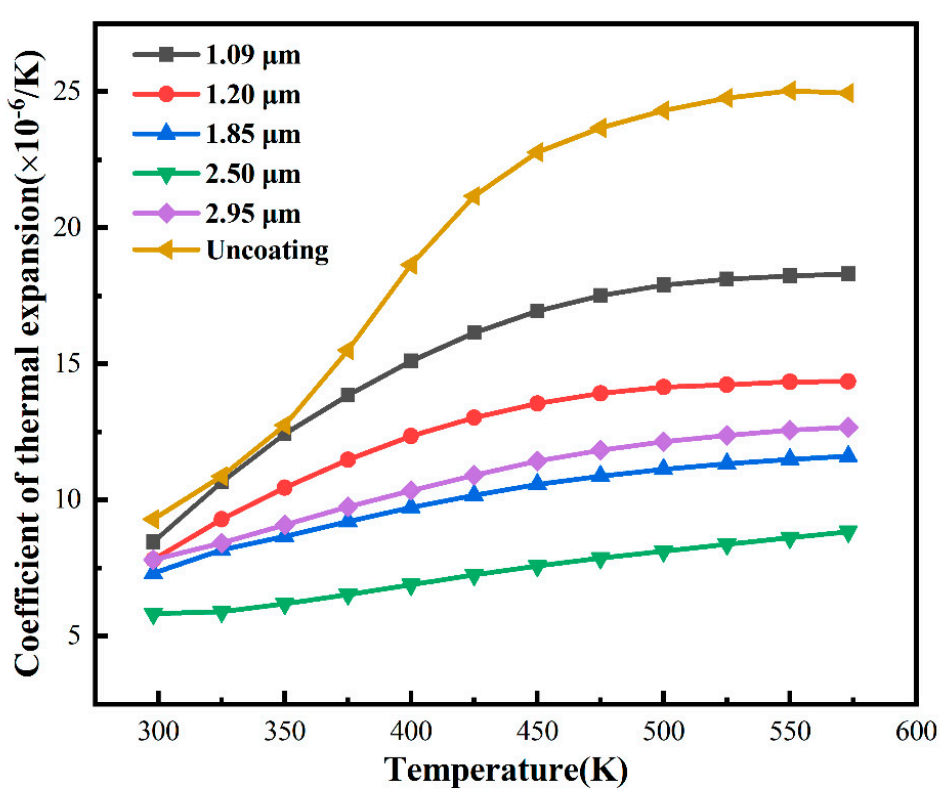

(b)

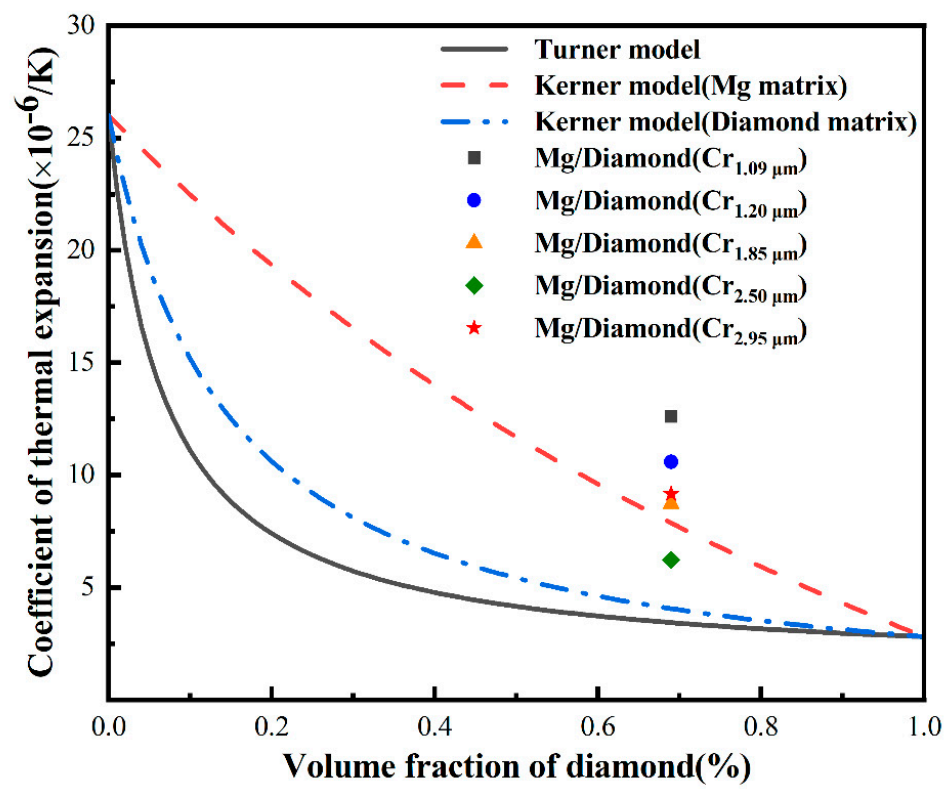

Figure 7. (a) Thermal expansion coefficient of $\mathrm{Mg} /$ diamond $(\mathrm{Cr})$ composites; (b) theoretical calculation and experimental analysis results of thermal expansion coefficient of $\mathrm{Mg}$ /diamond ( $\mathrm{Cr}$ ) compo-sites.

Figure $7 \mathrm{~b}$ shows the measured and theoretically expected CTE values of $\mathrm{Mg} /$ diamond composites. The Turner model and Kerner model were applied to calculate the CTE of $\mathrm{Mg} /$ diamond composites. 
The Turner model [30]:

$$
\alpha_{c}=\frac{\alpha_{m} V_{m} K_{m}+\alpha_{p} V_{p} K_{p}}{K_{m} V+K_{p} V_{p}}
$$

The Kerner model [31]:

$$
\alpha_{c}=\alpha_{m} V_{m}+\alpha_{p} V_{p}+V_{p} V_{m}\left(\alpha_{p}-\alpha_{m}\right) \times \frac{K_{p}-K_{m}}{V_{m} K_{m}+V_{p} K_{p}+\left(\frac{3 K_{p} K_{m}}{4 G_{m}}\right)} .
$$

The parameters used for calculations were as follows: $K_{m}=35.83 \mathrm{GPa}, K_{p}=580 \mathrm{GPa}$, $\alpha_{m}=26 \times 10^{-6} / \mathrm{K}, \alpha_{p}=2.8 \times 10^{-6} / \mathrm{K}, G_{M g}=18.2 \mathrm{GPa}$, and $G_{\text {Diamond }}=360 \mathrm{GPa}$ [32] In Figure $7 \mathrm{~b}$, the prediction result of the Turner model under the same conditions was significantly smaller than that of the Kerner model, because the more idealized Turner model ignores the shear stress at which a material undergoes thermal expansion. Furthermore, all the experimental results were higher than the calculated ones, with the only exception being the composites with an interface thickness of $2.50 \mu \mathrm{m}$, which fell within the prediction area of the Kerner model. This can be explained by the weak interfacial strength between $\mathrm{Mg}$ and the diamond particles. Therefore, an appropriate thickness of the interfacial layer can further improve the interface bonding of the composite, thus broadening the application fields of magnesium matrix composites.

\section{Conclusions}

In this paper, the effect of the $\mathrm{Cr}$ coating on the thermal properties of the $\mathrm{Mg} /$ diamond composites was investigated. The following conclusions were drawn:

1. The synthesis of the chrome carbide coatings was carried out using a molten salt process. Starting with a coating temperature of $950{ }^{\circ} \mathrm{C}$ and a holding time of $30 \mathrm{~min}$, a relatively complete coating was formed on the diamond surface. The coating process at $950{ }^{\circ} \mathrm{C} / 30 \mathrm{~min}, 950{ }^{\circ} \mathrm{C} / 60 \mathrm{~min}, 950{ }^{\circ} \mathrm{C} / 90 \mathrm{~min}, 1000{ }^{\circ} \mathrm{C} / 30 \mathrm{~min}$, and $1050{ }^{\circ} \mathrm{C} / 30 \mathrm{~min}$ could obtain an interface layer with a thickness in the range 1.09-2.95 $\mu \mathrm{m}$.

2. The density and thermal conductivity of the composite reached a maximum value of $97.24 \%$ and $202.42 \mathrm{~W} /(\mathrm{m} \cdot \mathrm{K})$, respectively, compared with the unmodified $\mathrm{Mg} /$ diamond composite, thus improving by $6.4 \%$ and $81.1 \%$, respectively.

3. The CTE of the $\mathrm{Mg}$ /diamond $(\mathrm{Cr})$ composite first decreased and then increased with the increase in coating thickness, reaching a minimum value of $5.82 \times 10^{-6} / \mathrm{K}$ at $2.50 \mu \mathrm{m}$ coating thickness, which was only $60 \%$ of the CTE of the uncoated $\mathrm{Mg} /$ diamond composite, thus effectively matching the thermal expansion coefficient of the semiconductor material.

In the molten salt process, due to the difference in surface energy between the diamond (100) and (111) surfaces, the deposition rate of carbides on the (100) is faster than on the (111) surface. If the coating temperature is too high and the holding time is too long, the coating on the (100) crystal surface will crack because it does not match the CTE of diamond.

$\mathrm{The} \mathrm{Mg}$ /diamond $(\mathrm{Cr})$ composite was prepared using the squeeze casting infiltration process under a pressure of $10 \mathrm{MPa}$. The density and thermal conductivity of the composite first increased and then decreased with the increase in coating thickness, mainly because the conversion of carbides could optimize the interface bonding, and the presence of thicker coatings and interface defects would produce higher interface thermal resistance, resulting in a decrease in thermal conductivity.

Author Contributions: Conceptualization, J.L. and R.P.; methodology, R.P. and J.L.; validation, J.L., X.X. and Y.Z.; resources, J.L., X.X., J.R. and J.W.; investigation, R.P., K.Z. and Y.Y.; writing-original draft preparation, R.P.; writing — review and editing, J.L. and R.P.; visualization, Y.Z.; supervision, Y.Z.; project administration, Y.Z. and J.L.; funding acquisition, Y.Z., J.L. and J.W. All authors read and agreed to the published version of the manuscript. 
Funding: This work was financially supported by National Natural Science Foundation of China (No. 51801073), the Natural Science Foundation of the Jiangsu Higher Education Institutions (No. 18KJB510007), and the Industry-University-Research Collaborative Innovation Foundation of Qilu University of Technology (Shandong Academy of Sciences) (2020-CXY38).

Institutional Review Board Statement: Not applicable.

Informed Consent Statement: Informed consent was obtained from all subjects involved in the study.

Data Availability Statement: Data are contained within the article.

Conflicts of Interest: The authors declare no conflict of interest.

\section{Nomenclature}

Symbols and acronyms

TC

thermal conductivity

CET

MMCs

coefficient of thermal expansion

$K_{c}$

metal matrix composites

$\alpha \quad$ thermal diffusivity $\left(\mathrm{m}^{2} / \mathrm{s}\right)$

$\rho_{c} \quad$ density of the $\mathrm{Mg} /$ diamond $(\mathrm{Cr})$ composite $\left(\mathrm{g} / \mathrm{cm}^{3}\right)$

$c \quad$ heat capacity $\left(\mathrm{J} \cdot \mathrm{g}^{-1} \cdot \mathrm{K}^{-1}\right)$

\section{References}

1. Razeeb, K.M.; Dalton, E.; Cross, G.L.W.; Robinson, A.J. Present and future thermal interface materials for electronic devices. Int. Mater. Rev. 2018, 63, 1-21. [CrossRef]

2. Zhang, S.; Xu, X.; Lin, T.; He, P. Recent advances in nano-materials for packaging of electronic devices. J. Mater. Sci. Mater. Electron. 2019, 30, 13855-13868. [CrossRef]

3. Dadkhah, M.; Saboori, A.; Fino, P. An overview of the recent developments in metal matrix nanocomposites reinforced by graphene. Materials 2019, 12, 2823. [CrossRef] [PubMed]

4. Shirvanimoghaddam, K.; Hamim, S.U.; Akbari, M.K.; Fakhrhoseini, S.M.; Khayyam, H.; Pakseresht, A.H.; Ghasali, E.; Zabet, M.; Munir, K.S.; Jia, S. Carbon fiber reinforced metal matrix composites: Fabrication processes and properties. Compos. Part A Appl. Sci. Manuf. 2017, 92, 70-96. [CrossRef]

5. Inyushkin, A.; Taldenkov, A.; Ralchenko, V.; Bolshakov, A.; Koliadin, A.; Katrusha, A. Thermal conductivity of high purity synthetic single crystal diamonds. Phys. Rev. B 2018, 97, 144305. [CrossRef]

6. Jacobson, P.; Stoupin, S. Thermal expansion coefficient of diamond in a wide temperature range. Diam. Relat. Mater. 2019, 97, 107469. [CrossRef]

7. Molina-Jorda, J.M. Nano- and micro-/meso-scale engineered magnesium/diamond composites: Novel materials for emerging challenges in thermal management. Acta Mater. 2015, 96, 101-110. [CrossRef]

8. Molina-Jorda, J.M. Multi-scale design of novel materials for emerging challenges in active thermal management: Open-pore magnesium-diamond composite foams with nano-engineered interfaces. Compos. Part A Appl. Sci. Manuf. 2018, 105, 265-273. [CrossRef]

9. Pan, Y.; He, X.; Ren, S.; Wu, M.; Qu, X. Optimized thermal conductivity of diamond/Cu composite prepared with tungstencopper-coated diamond particles by vacuum sintering technique. Vacuum 2018, 153, 74-81. [CrossRef]

10. Wang, L.; Li, J.; Catalano, M.; Bai, G.; Li, N.; Dai, J.; Wang, X.; Zhang, H.; Wang, J.; Kim, M.J. Enhanced thermal conductivity in $\mathrm{Cu}$ /diamond composites by tailoring the thickness of interfacial TiC layer. Compos. Part A Appl. Sci. Manuf. 2018, 113, 76-82 [CrossRef]

11. Zhu, C.X.; Cui, C.; Wu, X.W.; Zhang, B.W.; Yang, D.; Zhao, H.X.; Zheng, Z. Study on surface modification of diamond particles and thermal conductivity properties of their reinforced metal-based ( $\mathrm{Cu}$ or $\mathrm{Mg}$ ) composites. Diam. Relat. Mater. 2020, 108, 9. [CrossRef]

12. Xie, Z.; Guo, H.; Zhang, X.; Huang, S.; Xie, H.; Mi, X. Tailoring the thermal and mechanical properties of diamond/Cu composites by interface regulation of Cr alloying. Diam. Relat. Mater. 2021, 114, 108309. [CrossRef]

13. Yang, L.; Sun, L.; Bai, W.; Li, L. Thermal conductivity of Cu-Ti/diamond composites via spark plasma sintering. Diam. Relat. Mater. 2019, 94, 37-42. [CrossRef]

14. Li, J.; Wang, X.; Qiao, Y.; Zhang, Y.; He, Z.; Zhang, H. High thermal conductivity through interfacial layer optimization in diamond particles dispersed Zr-alloyed Cu matrix composites. Scr. Mater. 2015, 109, 72-75. [CrossRef]

15. Kumar, C.M.P.; Chandrashekarappa, M.P.G.; Kulkarni, R.M.; Pimenov, D.Y.; Giasin, K. The Effect of Zn and Zn-WO3 Composites Nano-Coatings Deposition on Hardness and Corrosion Resistance in Steel Substrate. Materials 2021, 14, 2253. [CrossRef] [PubMed] 
16. Kumar, C.M.P.; Lakshmikanthan, A.; Chandrashekarappa, M.P.G.; Pimenov, D.Y.; Giasin, K. Electrodeposition Based Preparation of Zn-Ni Alloy and Zn-Ni-WC Nano-Composite Coatings for Corrosion-Resistant Applications. Coatings 2021, 11, 712. [CrossRef]

17. Ying, T.; Chi, H.; Zheng, M.; Li, Z.; Uher, C. Low-temperature electrical resistivity and thermal conductivity of binary magnesium alloys. Acta Mater. 2014, 80, 288-295. [CrossRef]

18. Polat, S. Theoretical modeling and optimization of interface design to improve thermal conductivity in Mg-Dia composites. Ceram. Int. 2022, 48, 4763-4774. Available online: https://sciencedirect.53yu.com/science/article/pii/S0272884221034167 (accessed on 15 September 2021). [CrossRef]

19. Náprstková, N.; Novák, M.; Marek, M.; Šramhauser, K.; Sviantek, J.; Stančeková, D.; Ťavodová, M. Analyses of Influence on Chromium Coating after Grinding from the View of Final Microstructure and Microhardness in the Surface Layer. Materials 2021, 14, 2396. [CrossRef] [PubMed]

20. Ren, S.; Chen, J.; He, X.; Qu, X. Effect of matrix-alloying-element chromium on the microstructure and properties of graphite flakes/copper composites fabricated by hot pressing sintering. Carbon 2018, 127, 412-423. [CrossRef]

21. Stevenson, R.D.; Whatley, W.J.; Glatz, J.J.; McCoy, J.W. Aerospace, Defense, and Demanding Applications. Proceedings of the 3rd International Conference on Powder Met; SPIE: Bellingham, WA, USA, 1993; pp. 269-276.

22. Pickard, S.M.; Withers, J.C.; Loufty, R.O. High Thermal Conductivity Metal Matrix Composites. E.P. Patent 1680522B1, 4 June 2014.

23. Ma, H.; Wang, J.; Wang, H.; Dong, N.; Zhang, J.; Jin, P.; Peng, Y. Influence of nano-diamond content on the microstructure, mechanical and thermal properties of the ZK60 composites. J. Magnes. Alloys 2021. [CrossRef]

24. Behboudi, F.; Kakroudi, M.G.; Vafa, N.P.; Faraji, M.; Milani, S.S. Molten salt synthesis of in-situ TiC coating on graphite flakes. Ceram. Int. 2021, 47, 8161-8168. [CrossRef]

25. Jia, J.H.; Bai, S.X.; Xiong, D.G.; Wang, J.; Chang, J. Effect of tungsten based coating characteristics on microstructure and thermal conductivity of diamond/ $\mathrm{Cu}$ composites prepared by pressueless infiltration. Ceram. Int. 2019, 45, 10810-10818. [CrossRef]

26. Chu, K.; Jia, C.; Guo, H.; Li, W. Microstructure and thermal conductivity of Cu-B/diamond composites. J. Compos. Mater. 2012, 47, 2945-2953. [CrossRef]

27. Tan, Z.Q.; Li, Z.Q.; Fan, G.L.; Guo, Q.; Kai, X.Z.; Ji, G.; Zhang, L.T.; Zhang, D. Enhanced thermal conductivity in diamond/aluminum composites with a tungsten interface nanolayer. Mater. Des. 2013, 47, 160-166. [CrossRef]

28. Tavangar, R.; Molina, J.M.; Weber, L. Assessing predictive schemes for thermal conductivity against diamond-reinforced silver matrix composites at intermediate phase contrast. Scr. Mater. 2007, 56, 357-360. [CrossRef]

29. Martienssen, W.; Warlimont, H. Springer Handbook of Condensed Matter and Materials Data; Springer Science \& Business Media: Berlin/Heidelberg, Germany, 2006.

30. Turner, P.S. The Problem of Thermal-Expansion Stresses in Reinforced Plastics. 1942. Available online: https://ntrs.nasa.gov/ citations /19930093345 (accessed on 8 June 2021).

31. Kerner, E. The elastic and thermo-elastic properties of composite media. Proc. Phys. Soc. Sect. B 1956, 69, 808. [CrossRef]

32. Yoshida, K.; Morigami, H. Thermal properties of diamond/copper composite material. Microelectron. Reliab. 2004, 44, 303-308. [CrossRef] 